the chief gas examiner (Lord Rayleigh), and unless the appeal is sustained the case is referred back to the magistrate for the assessment of the amount to be paid. The gas companies have always strongly objected to these police court proceedings, and the committee recommends a modification of the existing provisions whereby, in future, police court proceedings will not be required when the chief gas examiner shall certify that the default is not substantial, or that it is not due to careless conduct at the works, the forfeitures in all such cases being left for assessment to the chief gas examiner. The committee also recommends that in the case of any disputes arising between the gas referees and the gas companies, they should be referred to the chief gas examiner, and that his decision should be conclusive and binding on both parties.

Important concessions to the companies are recommended by the committee with regard to the amount of sulphur impurity allowed. In addition to a relaxation of the stringency of the tests to be applied for the detection of sulphuretted hydrogen, it is suggested that the standards for the amount of sulphur present in the gas, other than sulphuretted hydrogen, should be abolished. The committee has been influenced in this decision by the consideration of the nuisance created near the works by the use of lime purification, and the danger to the men employed in connection with the process. At the same time, however, it is proposed that the official tests should continue to be made, and that the amount of impurity in each form contained in the gas should be ascertained and recorded.

In view of the increasing amount of gas used in incandescent burners and for heating and power purposes, it is considered desirable that the calorific value of the gas should be determined and recorded, but no standards are proposed, and photometrical data with flat flame burners, in addition to those already made with the standard Argand, are also suggested as desirable.

The report has been issued within five months of the date of appointment of the committee, and it is to be hoped in the interests of the public that the legislative action necessary to carry these suggestions into effect may be made with equal promptness.

\section{SEISMOLOGICAL NOTES.}

I $\mathrm{N}$ the Bollettino della Societa Sismologica Italiana, vol. ix., No. 7, Dr. A. Ricco gives an interesting paper on the relative values of gravity in the vicinity of Etna, Sicily, the Aiolian Islands, and southern Italy. The results are shown in two sketch maps, on which a series of lines having the appearance of isomagnetics pass through places at which the difference between the expected and the observed values for $g$ are equal. The smallest values for the anomaly or $g-\gamma$. are found round the summit of Etna, whilst maxima occur in the proximity of deep water about $80 \mathrm{~km}$. to the south-south-west and $150 \mathrm{~km}$. at Stromboli to the north. A similar but not so marked gradient is found in the vicinity of the Bay of Naples. Along the Apennines and in central Sicily the anomaly is small, and the gradient is gentle. 'These observations are discussed in relation to volcanic and seismic activity, orographic and geotectonic conditions. An obituary notice of Dr. Mosé Contarini, who died at the early age of twenty-eight, at the commencement of a promising career, and a catalogue of disturbances for July, 1902, complete the number.

In vol. ix., No. 8 , of the same publication, Dr. A. Cancani describes and analyses five seismograms relating to earthquakes with known origins. The peculiarity of these seismograms, copies of which are given, is that they were obtained on a high speed ( 72 to $97 \mathrm{~mm}$. per minute) smoked paper record receiving surface.

The diagrams are therefore sufficiently open to read periods of half a second, which periods refer to the preliminary tremors. From the interval in time between the commencement of these first movements and the commencement of the large waves, the distances of origins from Dr. Cancani's station in Rome are calculated. The accuracy of the results obtained therefore depend upon the accuracy with which these two phases of motion can be identified upon the seismograms. In the first earthquake considered these identifications are clear, but if the figures for the reNO. I 808 , VOL. 70] mainder are exact reproductions of the original seismograms, it seems extremely likely that very different results might be arrived at by different investigators. For writing pointers with a minimum of friction, Dr. Cancani uses the hanging aluminium indices of his colleague, Dr. Grablovitz. The cost per annum for the recording materials, which include 730 sheets of paper, gas or oil for smoking, and varnish for fixing the same, \&c., is about $3 l$. 15s. At the end of the number the earthquake registers are brought up to the end of August 1902 .

The Austrian Earthquake Commission publish in No. 22 (new series) observations made by Dr. W. Láska in 1902 in Lemberg. They refer to records obtained from ReubeurEhlert horizontal pendulums.

In the Mémoires of the Geological Committee of St. Petersburg, No. 9 (new series), Dr. V. Weber gives a detailed account of the earthquake which on January $3 \mathrm{I}$, 1902, destroyed Chemaka. The epifocal area appears to lie along the major axis of a series of elliptical isoseists, and a map on which these are shown also indicates the different degrees of destruction in various villages within the disturbed district.

The phenomena observed are similar to those noted with many large earthquakes.

Another publication received from Russia is the Bulletin de la Commission Centrale Sismique Permanante. It refers to records obtained in the months April, May, and June at Tiflis, Taschkent, Irkutsk, Dorpat, and Krasnoiarsk, at each of which stations there are one or more seismographs.

The contributions to seismological knowledge received from Japan are as usual both varied and interesting.

Following in the footsteps of Dr. C. G. Knott, Mr. A. Imamura, in the reports of the Physico-Mathematical Society of Tokyo, vol. ii., No. 8, discusses certain earthquake registers, with the result that he finds that seismic disturbances have not only been most frequent at the times of conjunction and opposition of the sun and moon, but also at the times of quadrature. The extent to which barometrical pressure may effect seismic frequency is to be found in the same journal, the author being Dr. F. Ömori. Another note by the same writer describes a horizontal pendulum controlled by an inverted pendulum. The former is $\mathrm{r} \mathrm{m}$. in height, and has a boom $\mathrm{I} \mathrm{m}$. in length which carries $50 \mathrm{~kg}$. With its control a period of one minute is obtained without difficulty.

Dr. Ōmori's most important work is contained in No. 15 of the Publications of the Earthquake Investigation Committee. It relates to the measurement of the vibrations of railway carriages as recorded by seismographs. For years past the balancing of locomotives and the state of the permanent way have in Japan been determined by means of these instruments, and the practical advantages leading to the saving of fuel and the detection of faults which have accrued are generally known. Here we have an elaborate extension of previous work which railway engineers may read with advantage.

At the end of this number an index is given to the contents of the sixty-three profusely illustrated series of volumes and parts which, since 1893 , have been issued by the Tokyo Earthquake Investigation Committee. Unfortunately for European readers, forty-seven of these publications are in Chinese idiographs. Amongst the latter we find reports upon seismographs, observations made in deep bore holes, notes upon magnetic disturbances which have preceded certain large earthquakes, many observations made for the purpose of determining the transit velocity of earthquake motion, observations relating to subterranean sound phenomena, observations upon sea waves, investigations relating to seismic frequency, reports upon faults, landslips and volcanoes, and a mass of material, all the result of patient investigation, which is of great importance to modern science. Many of the papers are of immediate value to those who have to construct in earthquake countries. No only has the Japanese Government encouraged its engineers to study the effects of earthquakes upon structures within its own territory, but lengthy reports upon the damage which took place in Assam in June, 1897, indicate that it was considered advisable to derive lessons from misfortunes in foreign countries, and for this reason missions of 
engineers and men of science have been sent not only to India, but to Manila, Italy, and other places. One set of instructive reports refers to destruction and shattering produced by movements closely approximating to those of actual earthquakes given to a platform on which masonry and other structures had been erected. This platform is in no sense a toy, but a large piece of apparatus actuated by powerful machinery. To say that these investigations have during the last ten years cost the Government of Japan $50,000 l$. is a modest estimate. The return for the same is seen in the new types of structures which are growing up in Japan, replicas of which have been adopted in British possessions and other places, the meaning of which is that danger to life and property resulting from seismic disturbances, if not averted, has been markedly mitigated.

Add twenty volumes issued by the Seismological Society to those published by the Investigation Committee, and we have eighty-three publications, the greater number of which are volumes, as Japan's contribution to recent seismological progress.

In consequence of not being acquainted with researches carried out in the Far East-and we do not refer to those which Japan for the benefit of her own people has published in Chinese characters-it is not uncommon to find seismologists in Europe reproducing as novelties the faits accomplis of past history. Had Prof. Odone read the Transactions of the Seismological Society of Japan, it is not likely that in a recent number of the Bollettino he would have given, with drawingrs almost identical with those published in Japan, a description. of a method by which the relative motion of two points of the earth's surface might be measured; neither should we find in the last number of the same journal a description, quoted from the Comptes rendus, January 26,1903 , of a new system by which record receiving surfaces could be set in movement, and therefore ready to receive the record of an earthquake before the earthquake itself arrived to actuate the indices of a seismograph. In 1884 in Japan nine stations were electrically connected, so that an earth movement at one of them resulted in the release of clockwork at all the others (Trans. Seis. Soc., vol. x.).

Since then the system has been greatly extended, and at stations considerable distances apart record receiving surfaces are set in motion before the pointers resting on the same have been actuated by earth movements. That work of this description, which was referred to over and over again in publications issued twenty years ago in Japan, should in 1904 be reproduced in Europe as original indicates that the work has at least had some slight recognition. The main point at issue, however, is that the veil of Chinese cryptograms which has hidden so very much of the work done in the Far East has by means of an index been partly raised, and if at Strassburg or at any other institution this work can be rendered available to seismologists who read a European language, the same will from " many an error free us," and be most gratefully received.

\section{UNIVERSITY AND EDUCATIONAL INTELLIGENCE.}

CAMBRIDGE.-The following appointments of university lectures are announced:-Chemistry, Messrs. W. J. Sell, F.R.S., and H. J. H. Fenton, F.R.S.; organic chemistry, Mr. S. Ruhemann; petrology, Mr. A. Harker, F.R.S.; invertebrate morphology, Mr. A. E. Shipley, F.R.S.; physical anthropology, Mr. W. L. H. Duckworth; palæozoology, Mr. H. Woods.

The new Balfour student is Mr. R. C. Punnett, of Caius College. A grant of $5 \mathrm{ol}$. from the Balfour fund has been made to Mr. L. Doncaster, King's, in furtherance of his researches on sex and heredity.

Messrs. C. Shearer and W. E. Agar have been nominated to occupy the university's table at the Naples Zoological Station.

The special board for biology proposes that Mr. J. W. Clark should be re-appointed a manager of the Balfour fund for a period of ten years.

$$
\text { No. I } 808 \text {, VOL. 7O] }
$$

The original researches of Messrs. R. Hosking, W. Makower, G. Owen, and F. Rogers, advanced students in experimental physics, and in engineering, have been approved by the special board for physics and chemistry as of distinction; they will receive certificates qualifying them for the B.A. degree for research.

Five candidates have gained the university diploma in agriculture; seven have qualified in the first part of the examination.

Mr. H. M. Chadwick, Clare, Mr. C. H. W. Johns, Queens', Dr. A. Macalister, St. John's, and Dr. F. H. H. Guillemard, Caius, have been appointed members of the new board of anthropological studies.

Dr. D. MacAlister, St. John's, has been appointed assessor to the regius professor of physic. Prof. Darwin, Trinity, and Prof. Larmor, St. John's, have been appointed electors to the Isaac Newton studentship in astronomy and physical optics.

Mr. Percy F. Kendall has been appointed professor of geology in the University of Leeds, and Dr. J. B. Cohen has been appointed professor of organic chemistry in the same university.

Mrs. Amanda W. Reed has, savs Science, provided in her will for the foundation of an institution at Portland, Oregon, to be known as Reed Institute, in memory of her husband, the late Simon G. Reed. The bequest will amount to about $400,000 l$. Her will specifies that the institute shall combine instruction in the fine arts, sciences, and manual training, and that it shall be conducted with especial regard to the needs of young men and women compelled to earn their own living.

New science buildings, which by special permission of Lord Kelvin have been called the Kelvin Science School, are to be opened by Sir Douglas Fox at Trent College, Derbyshire, on June 29. The new science school contains six large rooms and three small ones; these include a room for manual instruction in wood and iron, a physical laboratory, a lecture theatre to seat eighty, a balance room, a chemical laboratory for twenty-four students, and a biological laboratory for sixteen students.

A PAPER read by Prof. Israel C. Russell before the Research Club of the University of Michigan in January last is printed in Science for June 3. After referring to the triumphs of science in the last century, Prof. Russell remarked:-" The intellectual tide-gauges of the world give no suggestion that the nineteenth century wave of discovery has culminated. On the contrary, there is abundant evidence to show that the rate of intellectual development is still on the increase, and that yet more important conquests in the domain of the unknown than have illuminated the past will be made in the future." The recognition of the importance of research by the United States is naturally emphasised in the paper, and three important steps in this direction are marked by what Prof. Russell called "enduring movements," viz. the American Journal of Science, which appeared first in 1818 , the Smithsonian Institution, and the Carnegie Institution. Speaking of the place of research in the university, Prof. Russell expressed his agreement with the dictum of Sir Norman Lockyer, that " research is now generally acknowledged to be the most powerful engine of education that we possess."

THE twenty-eighth annual exhibition of work executed in the public elementary schools founded by the late London School Board, and now administered by the London County Council, was held from June 13 to 18 at the Medical Examination Hall, Victoria Embankment. As in previous years, one section of the exhibition was devoted to the science work done in these schools. The exhibits were chiefly pieces of apparatus and working models made or arranged by pupils and teachers. It was satisfactory to notice that the work of pupils and teachers was this year kept separate, and the confusion which in some former years resulted from an indiscriminate intermingling of the exhibits of teachers and taught was fortunately avoided. Much of the work shown was the joint product of the science 